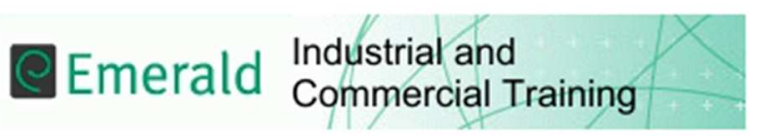

High-Performance Teams and Job Involvement: Exploring the Linkage to Augment Quality in Indian Education and Research

\begin{tabular}{|r|l|}
\hline Journal: & Industrial and Commercial Training \\
\hline Manuscript ID & ICT-09-2017-0075.R1 \\
\hline Manuscript Type: & Article \\
\hline Keywords: & $\begin{array}{l}\text { Benchmarking, Higher Education, High Performance Teams, Job } \\
\text { Involvement Level, Quality }\end{array}$ \\
\hline \multicolumn{2}{|c}{} \\
\hline
\end{tabular}

SCHOLARONE ${ }^{\text {IM }}$

Manuscripts 


\title{
High-Performance Teams and Job Involvement: Exploring the Linkage to Augment Quality in Indian Education and Research
}

\begin{abstract}

\section{Purpose:}

Indian higher education is arguably 'in the doldrums'. Conformity to minimum standards and requirements combined with ever-eroding quality is the serious threats. Many researchers have suggested adopting a functional approach in universities and developing greater autonomy and accountability to improve the situation. The present paper deliberates on the introduction of an integrated way of making teachers more involved in their profession with the intention of enhancing the quality of education and research.
\end{abstract}

\section{Design/methodology/approach:}

The paper's argument conceptualizes the possibilities of Indian higher education system benchmarking the concept of high-performance teams as practiced in the industry.

\section{Findings:}

Taking the support from the extant literature, it is proposed that working in high-performance teams have the potential to elevate the involvement level of the faculty. Furthermore, it is suggested that through the implementation of high-performance teams in educational settings, teachers would also be able to develop their competencies in relation to research activities.

\section{Originality/value:}

The model presented in the study has the potential to be empirically tested for its validity and reliability, which opens vistas for future research.

\section{Keywords:}

Benchmarking, Higher Education, Job Involvement Level, High-Performance Teams, Quality

\author{
Article Classification: Conceptual Paper
}




\section{High-Performance Teams and Job Involvement: Exploring the Linkage to Augment Quality in Indian Education and Research}

Over 750 Universities and more than 40000 colleges with around 28 million students and around 1.5 million teachers make India the third largest system of Higher Education (HE) in the world. The demand for HE is growing at the rate of 20 percent per annum in India (Gupta, 2008). The world's attention is on India as a global hub for international education, especially in the light of its large youth population. Thus, India has the possibility of attracting students to its universities but only if it is able to demonstrate a quality education system. Equally, India may wish to build international linkages and partnerships through the guarantee of quality education. From both perspectives, the essence is grounded in the term "quality education". However, this is particularly jeopardized by the present weaknesses in terms of quality in the Indian education system. India does, of course, have its own mechanism and apex bodies to check and evaluate the quality in education; however, so far these bodies have not been able to carry out their role in a comprehensive manner. India's quality assurance systems are still undergoing reforms and there exists incoherence in policy formulation and implementation (Parashar \& Parashar, 2012), which has always invited questions and doubts from the stakeholders. Literature suggests that these systems work on a fault-finding approach rather than a suggestive or a consultative approach. Since assessment tends to be only on an annual basis, the results of the assessment can sometimes be very different from the reality. Institutions undergoing the assessment, prepare well in advance for the inspection visit and manipulations can be a common phenomenon. Once the ratings are declared, many institutions return to their regular routine behaviour.

The UNESCO definition of quality in HE describes it as a multi-dimensional, multilevel, and a dynamic concept (Vlãsceanu, Grünberg, \& Parlea, 2004). This definition talks about the standards and the outcomes and hence, in general, the emphasis is on the measures of quality. However, measures alone can not bring the quality and hence what is required are the drivers of quality education and research. One such driver which has been consistently identified in the education literature is the teacher/faculty. There is a plethora of research identifying varied aspects related to the teacher that impacts the quality of education and research i.e. qualification, competence, commitment, and involvement etc. The study focuses on the involvement level of 
teachers in their profession as one of the key drivers of quality in the Indian HE system. It attempts to explore if the concept of high-performance teams (HPTs) as practiced in the industry, be implemented in HE sector using the benchmarking tools and techniques to increase the involvement levels of teachers.

\section{Benchmarking as a Tool}

In the contemporary era, benchmarking techniques are commonly used as a tool for development in various fields (Sweet et al., 2007). They are now widely accepted and used for quality improvement in both manufacturing as well as service industries, including education sector, however, with varying style and intensity. The term 'benchmarking' as described by Bendell (1993) is "the process of identifying and learning from best practices anywhere in the world in the quest for continuous improvement." Daniels (1996) refers benchmarking as the process of comparing one's own organization with its peers worldwide, to identify and learn from best practice. It is thus characterized as a drive for 'excellence, involving a continuous quest for improvement. Benchmarking, initially coined by Rank Xerox to describe a process of self-evaluation and self-improvement through the systematic and collaborative comparison of practice and performance with competitors in order to identify own strengths and weaknesses, and learn how to adapt and improve as conditions change (Camp, 1989), was first noted in United Kingdom HE in 1957 (Jackson, 2001), with reference to standards of students. However, since that time it has been applied in a number of ways to various organizational processes and mechanisms.

Benchmarking activities are classified into various types according to the nature of the processes such as, for example, implicit or explicit, individual or collaborative, internal or external, vertical or horizontal and metric or bureaucratic (Jackson, 1998). A benchmarking exercise might rely exclusively on one particular approach or it might utilize a combination of approaches. The literature is full of traditional and generic benchmarking (Moreland et al., 2000) techniques through which the processes are improved either with partnerships or the reference points of similar kind and nature. A different approach was offered in the early stages of benchmarking by the chairman of the Confederation of British Industry Benchmarking Initiative (Survey of Benchmarking in the UK: Executive Summary, 1993) who argued that "Benchmarking denotes an attitude of mind that is intellectually curious, penetrating, objective, and impatient for improvement." When benchmarking itself refers to an intellectually curious and penetrating attitude of mind, then this provides scope for the techniques followed therein to be employed creatively. However, generally, the 
benchmarking is done against the comparable process in any other organization where the process is being carried successfully. The analysts of the organization study and analyze their own process in the light of the benchmarked process and try to locate the lacunae and overcome them by learning from the benchmarked process. In the education sector, benchmarking is by and large applied to develop the academic and administrative processes such as course design, curriculum development, admission process, fee structures, etc., but so far that is also in the traditional approach - course design is benchmarked against the other institutional course design, curriculum is matched with the other best curriculum and admission process is benchmarked against another sound admission process and so on.

Moreover, not much literature is available in the Indian context in relation to benchmarking and especially in relation to HE. The Indian HE system is constituted mostly of the affiliated colleges and some universities and not the islands of vaunted quality education (Indian Institutes of Management (IIMs), Indian Institutes of Technology (IITs) and National Institutes of Technology (NITs) or other University departments. It is particularly in the college sector where there is a pressing need to increase the quality of education. The college sector takes few measures to apply any benchmarking techniques to improve upon various processes. However, the question is, even if they apply the techniques whether it will improve the quality of education? Improving the systemic processes and improving the curriculum in HE settings will not improve the quality until, or unless, there is an improvement in the education delivery which in turns depends on the teacher. The ultimate responsibility of "quality" in the education sector rests with the teacher who has to be supported by other management functions with proper resources.

\section{High-Performance Teams (HPTs)}

A plethora of research (Hackman, 2004; Manfred, 1999; Katzenbach et al., 1993) and practices have proved that the teams if properly supported to become HPTs, can achieve far better results. Thompson et al. (1998) argued that HPTs can lead to higher productivity, better quality, and a close focus by workers on what organizations really are supposed to be doing. Even an average team achieves $63 \%$ of the objectives of their strategic plans (Michael, 2005) however HPT groups are capable of far exceeding this. Salas et al. (2004) define team as "a distinguishable set of two or more people who are assigned specific roles or functions to perform dynamically, interdependently, and adaptively toward a common and valued 
goal/object/mission, who have each been assigned specific roles or functions to perform, and who have a limited lifespan of membership."

HPTs or High-Performance Work Teams (HPWTs) are the evolved concepts of 'teams' which businesses are successfully using to make their management and staff more productive and their companies more profitable. Fisher (1993) and Orsburn et al. (1990) affirmed that teamwork systems essentially have dominant characteristics of increased autonomy, transfer of skills and responsibilities and opportunity to rotate through the jobs. Rickards and Moger (1999) define seven factors to distinguish HPTs which are a strong platform for understanding, shared vision, creative climate, ownership of ideas, resilience to setbacks, network activators and learn from experience. Further, Katzenbach and Smith (1993) argue that it is a strong sense of personal commitment, which distinguishes HPTs from other teams. This way HPTs resembles communities of practice as both runs on shared passion, which would link to their corresponding high level of involvement (Castka et al., 2001). Warrick (2016) suggests teamwork to be of high priority and that leaders in organizations of all types and sizes from private, public, nonprofit, athletic, military and other sectors should develop high-performance teams. Moreover, business consultants have advocated the use of teams in educational settings (Colbeck, 2000). Consequently, the application of teams in an educational setting is inevitable in the form of self-managed teams (Varney, 1994) working as HPTs. The functional approach of HPTs in HE setting would be to leverage on collaboration, shared resources and increased knowledge and expertise, which is expected to deliver high-quality teaching and research outcomes. Course and curriculum development, co-teaching, co-authorship on research and consultancy projects are some of the ways in which the concept of HPTs can be implemented. HPTs contribute to the learning within the team as well as across the teams through multiple memberships and therefore contributes to organizational learning. Also, the clarity of goals and shared vision and active participation and contributions increases the engagement levels. Therefore, the study aims at exploring the ways in which the fruits of teamwork can be extracted in the most effective manners in educational settings.

\section{Job Involvement Level}

HPTs are intrinsically connected to job involvement levels. Job involvement levels may be taken as the extent or the degree of intensity to which an individual feels enthusiastically 
involved, attached and to his/her job. It is the degree to which one is cognitively preoccupied with, engaged in, and concerned with one's present job (Paullay et al., 1994). In much literature, job involvement and work engagement are considered to be same and these terms are even used interchangeably as well as to define each other. John Kammeyer-Mueller, University of Florida defines it as active engagement in one's work. However, as per Hallberg (2006) "work engagement is positively related with, but can nevertheless be differentiated from, similar constructs such as job involvement and organizational commitment." Involvement differs from other constructs in the sense that it is a deeper state of psychological attachment and absorption in one's work tasks. The purpose of the study is not to differentiate between involvement, commitment, and engagement and, because of their relatedness; all the terms are used for finding the impact of striving for quality while working in teams. Involvement level of lecturers in their profession is frequently considered to be one of the key determinants for the delivery of quality education i.e. service quality. However, Mosahab et al. (2010) are of the opinion that research into service quality in educational organizations is somewhat scant. Raju and Srivastava (1994) have emphasized the point that "the more dependable and psychologically participative behavior on the part of teachers on one hand, and educational outcomes and the students' intellectual and personal development on other, depend largely on the commitment of the teachers." They have also stated the basic psychological determinants of job involvement as choice satisfaction, interest in the profession, desire to utilize skills, group attitude and intention to stay with the profession. The present study is an attempt to set up a relation between the teamwork and abovementioned determinants.

\section{Conceptualization and Discussion}

As per Cai-feng (2010), education today is tomorrow's economy and is becoming an important source of power. He also highlights the importance of education stating it to be the strategic fundamental industry in the age of knowledge-based economy. However, Indian HE is in a static state. The issue of reducing quality is a serious threat to Indian HE. Engelkemeyer (1995) categorized key shortcomings of contemporary HE systems as poor teaching. Misra (2002) identifies "management without objectives" as one of the key reasons for the downfall of the Indian university system. He highlights the need for - adopting a functional approach in our universities; periodic academic audits; greater autonomy and accountability in all spheres of operations; open door policy welcoming ideas and people from all over; administrative restructuring decentralizing university departments and schools; 
and making education relevant to our people and times; as the basic steps in improving the Indian universities. The World Declaration on Higher Education (1998) declared that "quality in higher education is a multi-dimensional concept." But, both Misra and the World Declaration on Higher Education appear to overlook one of the key drivers of education quality - the teacher.

The teacher acts as a central protagonist for knowledge dissemination. A paradigm shift is required in the approach of HE systems to think in new and integrated ways of making teachers more involved in their profession. The complex array of associated issues deserves a complete rethinking of our approach to higher education (Umashankar et al., 2007). For this purpose, the paper suggests a novel approach through benchmarking. The proposed model (Figure 1) is constituted of a range of benchmarking approaches which, per se, are not novel in regards to its origins but in the education sector. Hitherto, the primary reference point is industry and applied corporate settings rather than educational settings and this highlights the difference in the nature of two environments. In India, HE institutions are becoming increasingly aggressive in their marketing activities by benchmarking their marketing practices against those of the corporate sector, but they fail to show the same passion in, for example, research activities or towards the efforts to improve the processes or the quality of education. When the definition of benchmarking itself states that it is the quest for improvement and learning from the best practices, then the point should be to learn from the practice rather than to copy the practice as it currently exists. Introducing a more flexible attitude in this manner allows the possibility of learning wherever we deem fit and in whatever way we want.

It is evident from the literature that benchmarking as a tool has been proven to be effective in a range of contexts. For example, Ruiz, Segura, and Sirvent (2015) have demonstrated benchmarking as a tool for identifying best practices in Spanish universities. Similarly, Lee and Kim (2014) and Montoneri, Lee, Lin and Huang (2011) have advocated the use in various contexts, including educational, of benchmarking models. Thus, this technique can also be adopted in Indian educational settings. Normally, in benchmarking, the benchmarked process is thoroughly studied and, in the light of this, individual processes are developed. However, in the educational setting the concept of 'team' is a rare phenomenon and therefore it is to be developed from scratch. The concept of HPTs in corporate settings can be readily benchmarked and studied and on the basis of this learning with minor modifications, intradepartment teams, and multi-disciplinary inter-department teams can be worked out. Rickards 
and Moger (1999) also state the importance of necessary support for newly formed teams. Furthermore, a clear understanding should be developed among all the members of the teams regarding the objective of the benchmarking.

Despite the widespread use of teams in almost all types of organizations, it is difficult to find any research for teams in HE in India. Stehr (2002) writes "The transfer of knowledge is part of a learning and discovery process that is not necessarily confined to individual learning." The nature of teams in an educational setting will be heterogeneous. As per the findings of a recent study carried by Yair Holtzman and Johan Anderberg (2011), "a heterogeneous team composition could optimize efficiency, quality, and innovation." They have stressed the importance of diversity and collaboration among teams by stating:

"We believe that diversity in team members' skill sets is critical for breakthrough results and external collaboration has the potential to add significant value to all parties involved"

But at the same time, they also argue we should neither overlook nor underestimate the value of the basic essential ingredients that are required for team success. They also provide the critical success factors for teams (see Holtzman and Anderberg, 2011). Altbach (2005) remarks "world-class universities require world-class professors and students - and a culture to sustain and stimulate them." Teams, aiming to reap the benefits of learning through sharing could act as a stimulus to get utmost involvement levels from the teachers. Another benefit of having teams in an educational setting can be the nature of teams itself - interdisciplinary. In a study on more than 17,000 patents, Fleming (2004) showed that breakthrough innovations are more likely to arise out of teams made up of people from very diverse disciplines. On the other hand, his research also indicates that the average value of innovations will be higher when the team is comprised of individuals from similar disciplines. Likewise, Hsu, Lee, and Lin (2010), showed that individual researchers are more efficient than research teams in applying for patents; however, research teams are superior to individual researchers in terms of passing rate and quality of patents granted. This endorses the implication of teams in augmenting quality. Meier (2008) quoted "When we're faced with what looks at first like an unsolvable problem, a team with what I call 'spikes' of different talents will come up with a better solution than a team whose members have similar strengths." Well-structured and innovative models can be developed to apply the concept of high-performance intra-discipline and inter- 
discipline teams to generate quality performance in terms of research work and course delivery. To elaborate the point it will be useful to take an example. A professor working in one particular department is very good at research methods and techniques. S/he is a learned person having vast and diverse experience. In the coming two years $\mathrm{s} / \mathrm{he}$ will retire or make a shift from present university to some other. Once gone, s/he takes away all her/his learning and expertise. This is what actually happens in practice. The organization (university) in this example has failed to create a learning system in which it may ensure that whatever time an individual spent with the organization, his/her expertise and knowledge is disseminated through the organization in such a way that in case the individual plans to leaves, organization is assured that the event will add to the existing knowledge inventory as someone new will join the organization.

Nonaka and Takeuchi (1995) both agree that the individual learning is irrelevant for organizations unless such knowledge is disseminated through the organization where teamwork is the core tool for this dissemination. These teams are however not the informal groups which at times play politics. The purposive teams are therefore required in educational settings because of the inevitable formation of informal groups based on certain likings and disliking which affect the effectiveness of education delivery. The purposive teams will, however, harness the results in terms of informal learning as well. Informal learning refers to activities initiated by people in work settings that result in the development of their professional knowledge and skills (Cofer, 2010). Teams in educational institutions especially in HE shall induce the informal learning based culture which will further spur the quality research. The US Bureau of Labor Statistics reports that 70 percent of new learning is acquired through informal learning in the workplace (Benson, 1997). Acknowledging the fact that each individual is talented, in one or the other ways, and is blessed with different abilities and potentialities, we must realize that the planned collaboration of such individuals will definitely yield something which they alone could never produce. The reason behind this is that every individual has certain limitations and gaps in knowledge which can be filled by others. In other terms, the weaknesses of one can be shadowed by the strength of others. Then only the real purpose of education is served and the actual learning takes place. The collaboration of interdisciplinary teams can be thus adopted as one high involvement work systems (Buren and Werner, 1996) intended to increase organizational performance. However, many academicians still strongly doubt that in an educational setting, teams will be able to work efficiently because of reasons such as individuality and autonomy, with which a 
faculty works, differences in modus operandi, dissimilar focus and inclination, possible lack of coordination and so on. For this, McDonough (2001) has to say that the most effective team is relatively self-governed, reflecting constructively on, and managing its own internal processes. Also, Fraser et al. (2010) affirm that one who experiences a greater variety of functional flexibility may in fact exhibit higher levels of team effectiveness when working in groups.

Senge (1990) defines the "Learning Organization" as one "where people continually expand their capacity to create the results they truly desire, where new and expansive patterns of thinking are nurtured, where collective aspiration is set free, and where people are continually learning how to learn together." There should not be any other organization than the educational institutions of HE which should ideally be regarded as exemplary learning organizations. But sadly it is not true. In spite of being the source and the creator of knowledge, these institutions have often failed to be termed 'learning organizations'. Many authors have written much about informal learning, its importance, characteristics, factors affecting and how it develops knowledge (Billett, 2001; Ellstrom, 2001; Boud and Middleton, 2003; Ellinger, 1999; Kwakman, 2003; Doornbos et al., 2004). The lessons can be taken from above-mentioned studies of different authors to actually implement the concept. Authors like Rus, Chirică, Raţiu, and Băban (2014) have tried to study the learning organization concept in the context of Romanian Higher Education Institutes. If a culture, with the indispensable support from the management, is infused, then this will result in inculcating the team behaviors among teachers. Park et al. (2005) argue that teachers showing higher levels of teamwork behaviors perceived a higher level of team commitment. This will further lead to the higher involvement level and alleviation of quality in education and research (Figure 2). The study is not aimed at establishing significant relationships between excellence in teaching and research performance. Brew (1999) said "the belief that research activity benefits teaching and the student learning experience, has remained strong in the myths of academia while being difficult to support with empirical evidence." But the efforts are made by the author to strengthen the belief that the high involvement of faculty members in their profession can definitely promote research culture and excellence in teaching. Highly involved teachers will be physically, cognitively, emotionally and mentally into their role while performing (Khan, 1994). The analysis of the literature studied has led to the development of a model (Figure 1) wherein corporate High-Performance Teams (HPTs) are 
benchmarked in Indian HE to elevate the involvement level of teachers in their profession so as to advance the quality education and research.

\section{Proposed Model and its Implications}

Figure 1 presents the conceptual model of benchmarking industry-practiced HPTs in HE setting. To bring about any change in the organization, the top management or the leaders of the organization (universities or educational institutions in this case) have a great role to play. Likewise, in order to bring the concept of HPTs to the education sector, the top management/leaders have to sponsor/champion it and provide all the required resources both in financial and non-financial terms. Another important aspect is that of trust. Having a confidence in the concept of HPTs and in the employees that they'll be able to reap the benefits is quite important. Alongside, the governance and control mechanisms have to be very strong to ensure that things are moving in the right direction.

Benchmarking literature shows that there are lot many benchmarking process models with a different number of steps and phases being practiced in the industry (Anand and Kodali, 2008). Also, there is no fixed criteria and parameters for the formation of HPTs. Therefore, the model keeps it open to the individual institutions to pick the model of their choice which suits the specific needs and also to create an HPT as per their own requirements. This highlights the importance of autonomy to be given for creating and developing the HPTs. The members should be allowed to experiment without the fear of failure and setbacks and that's how to develop resilience amongst the members. The only thing to keep in mind that the purpose and the goals of HPTs should be very clear to its members. People in educational institutions may create intra-department or interdepartment teams. The success of these teams, however, depends on many factors such as the composition of the team, informal learning, complementary expertise, collaboration, competency building and working on projects. These teams can work on curriculum and programme development, research and consultancy projects, coteaching a course etc. Working in an HPT increases the responsibility of an individual member towards the group success and thus increases the participation which is intrinsically involving and rewarding. The more involved a teacher is with his/her job the quality in terms of delivery and dissemination of knowledge increases as well as the quality of research outcomes increases. 
The proposed model opens vistas of future research on HPTs in an educational setting and to empirically validate the potential use of benchmarking techniques. It also provides insights for educational institutions to address the quality concerns as more and more ranking agencies have started looking at the quality aspect both in education delivery and research.

\section{Conclusion and Scope for Future Research}

Benchmarking HPTs in Indian HE has the potential to elevate the involvement level of teachers in their profession. The study of extant literature supports that the interdisciplinary teams with greater autonomy and resilience can produce amazing results. Implementation of HPTs in the education sector will also reap the benefits of informal learning and teachers would be able to develop their competencies. The culture so developed would urge the teachers to improve upon their delivery part and spur the willingness to participate in quality research activities and thus overall increasing the 'quality' in Indian HE. The present study has the full potential to be empirically tested for its validity and reliability, thus authors suggest implementing the proposed model in an educational setting to add significant value. The process can be slow and hard to implement and but it can yield spectacular results.

However, it is important to note that the nuances and dynamics of HPTs in HE setting may differ from that of other contexts and therefore, it is expected that antecedents to the team effectiveness in HE setting would also be different. Future research work can be undertaken in this direction to identify these antecedents. Lately, the team literature has also explored the underlying mediating mechanisms in the relationship between team effectiveness and its potential antecedents for e.g. trust in the team (Lau and Liden, 2008) and shared mental models (Dionne et al., 2010). These mediating mechanisms can also be explored and validated for HE setting. The future work may also include the perspectives of team development interventions such as to suggest how to develop, sustain and maximize the effectiveness of such teams. 


\section{References}

1. Altbach, P.G. (2005), "Higher education in India", The Hindu, 12 April.

2. Anand, G., and Kodali, R. (2008), "Benchmarking the benchmarking models", Benchmarking: An International Journal, Vol. 15 No. 3, pp.257-291.

3. Bendell, T., Boulter, L., and Kelly, J. (1993), Benchmarking for Competitive Advantage, Pitman, London.

4. Benson, G. (1997), "Informal training takes off”, Training and Development, Vol. 51 No. 5, pp. 93-4.

5. Billett, S. (2001), "Learning through work: workplace affordances and individual engagement", Journal of workplace learning, Vol. 13 No. 5, pp. 209-14.

6. Boud, D., and Middleton, H. (2003), "Learning from others at work: Communities of practice and informal learning", Journal of workplace learning, Vol. 15 No. 5, pp. 194-202.

7. Brew, A. (1999), "Research and teaching: changing relationships in a changing context”, Studies in Higher Education, Vol. 24 No. 3, pp. 291-301.

8. Cai-feng, W. (2010), “An Empirical Study of the Performance of University Teachers Based on Organizational Commitment, Job Stress, Mental Health and Achievement Motivation” Canadian Social Science, Vol. 6 No. 4, pp. 127-140.

9. Camp, R.C. (1989), Benchmarking: The search for industry best practices that lead to superior performance, ASQC Quality Press, Milwaukee, WI.

10. Castka, P., Bamber, C.J., Sharp, J.M. and Belohoubek, P. (2001), "Factors affecting successful implementation of high performance teams", Team Performance Management: An International Journal, Vol. 7 No. 7/8, pp. 123-134.

11. Cofer, D.A. (2000), Informal Workplace Learning, Practical Application Brief No. 10, Center of Education and Training for Employment, Columbus, $\mathrm{OH}$.

12. Colbeck, C.L., Campbell, S.E., and Bjorkland, S.A. (2000), "Grouping in the dark", Journal of Higher Education, Vol. 71, pp. 60-83.

13. Daniels, S. (1996), “Benchmarking”, Work Study, Vol. 45 No. 3, pp. 18-20.

14. Dionne, S. D., Sayama, H., Hao, C., and Bush, B. J. (2010), “The role of leadership in shared mental model convergence and team performance improvement: An agentbased computational model”, The Leadership Quarterly, Vol. 21, pp. 1035-1049.

15. Doornbos A.J., Bolhuis, S., and Simons, P.R.J. (2004), "Modeling work-related learning on the basis of intentionality and development relatedness: a non educational perspective”, Human Resource Development Review, Vol. 3 No. 3, pp. 250-74. 
16. Ellinger, A.D. (1999), “Antecedents and consequences of coaching behavior", Performance Improvement Quarterly, Vol. 12 No. 4, pp. 45-70.

17. Ellstrom, P.E. (2001), "Integrating learning and work: problems and prospects", Human Resource Development Quarterly, Vol. 12 No. 4, pp. 421-35.

18. Engelkemeyer, S.W. (1995). "Total quality: a mechanism for institutional change and curriculum reform", in Roberts, H.V. (Ed.), Academic Initiatives in Total Quality for Higher Education, ASQC, Milwaukee, WI.

19. Fisher, K. (1993), Leading Self-directed Work Teams: A guide to Developing New Team Leadership Skills (pp. 13-15), McGraw-Hill, New York.

20. Fleming, L. (2004), "Perfecting cross-pollination", Harvard Business Review, Retrieved from https://hbr.org/2004/09/perfecting-cross-pollination.

21. Friedman, T.L. (2005), The World Is Flat: A Brief History of The Twenty-First Century, Straus and Giroux, Farrar.

22. Gupta, A. (2008), "International trends and private higher education in India", International Journal of Educational Management, Vol. 22 No. 6, pp. 565-594.

23. Hackman, J.R. (2004), Leading Teams: Setting the stage for great performances. Harvard Business School Press, Cambridge.

24. Hallberg, U., and Schaufeli, W.B. (2006), “'Same same' but different: Can work engagement be discriminated from job involvement and organizational commitment?", European Journal of Psychology, Vol. 11, pp. 119-127.

25. Holtzman, Y. and Anderberg, J. (2011), "Diversify your teams and collaborate: because great minds don't think alike", Journal of Management Development, Vol. 30 No. 1, pp. 75-92.

26. Jackson, N. J. (1998), "Introduction to benchmarking assessment practice", in Jackson, N. (Ed.), Pilot Studies in Benchmarking Assessment Practice in UK Higher Education, Quality Assurance Agency for Higher Education, Gloucester.

27. Jackson, N. J. (2001), "Benchmarking in UK HE: an overview", Quality Assurance in Education, Vol. 9, pp. 218-35.

28. Kahn, W. A. (1990), "Psychological conditions of personal engagement and disengagement at work", Academy of Management Journal, Vol. 33, pp. 692-724.

29. Katzenbach, J. and Smith, D. (1993), The Wisdom of Teams, Harvard Business School Press, Cambridge.

30. Kwakman, K. (2003), "Factors affecting teachers' participation in professional learning activities", Teaching and Teacher Education, Vol. 19 No. 2, pp. 149-70. 
31. Hsu, L. A., Lee, K. H., and Lin, C. C. (2010), "A comparison of individual and team research performance: A study of patents in III," PICMET 2010 TECHNOLOGY MANAGEMENT FOR GLOBAL ECONOMIC GROWTH, Phuket, pp. 1-6.

32. Lau, D. C., and Liden, R. C. (2008), “Antecedents of coworker trust: Leaders' blessings", Journal of Applied Psychology, Vol. 93, pp. 1130-1138.

33. Lee, H., and Kim, C. (2014), "Benchmarking of service quality with data envelopment analysis", Expert Systems with Applications, Vol. 41 No. 8, pp. 37613768.

34. Manfred, K. (1999), "High Performance Teams, Lessons from the Pygmies", Organizational Dynamics, Vol. 27 No. 3, pp. 66-77.

35. McDonough, E.F., Kahn, K.B. and Barczak, G. (2001), "An investigation of the use of global, virtual, and collocated new product development teams", Journal of Product Innovation Management, Vol. 18 No. 2, pp. 110-20.

36. Meier, S. (2008), "Building and managing an effective project team", Defense AT\&L, September-October, pp. 38-41.

37. Misra, R.P. (2002), "Globalization and Indian universities - challenges and prospects" Unpublished speech, Third Dr Amarnath Jha Memorial Lecture, Lalit Narayan Mithila University, Darbhanga, Bihar, 2 September.

38. Montoneri, B., Lee, C-C., Lin, T.T. and Huang, S-L. (2011), “A learning performance evaluation with benchmarking concept for English writing courses", Expert Systems with Applications, Vol. 38 No. 12, pp. 14542-14549.

39. Moreland, N., Jawaid, A. and Dhillon, J. (2000), "Quality improvement in the TESOL curriculum: a generic benchmarking approach", Quality Assurance in Education, Vol. 8 No. 2, pp. 57-62.

40. Mosahab, R., Mahamad, O. and Ramayah, T. (2010), “Comparison of Service Quality Gaps among Teachers and Students as Internal and External Customers", International Journal of Marketing Studies, Vol. 2 No. 2, pp. 13-20.

41. Nonaka, I. and Takeuchi, H. (1995), The Knowledge Creating Company. How Japanese Companies Create the Dynamics of Innovation, Oxford University Press, Oxford.

42. Orsburn, J. D., Moran, L., Musselwhite, E., and Zenger, J. H. (1990), Self-Directed Work Teams. The New American Challenge (pp. 8), Business One Irwin, Homewood, IL. 
43. Parashar, A.K., and Parashar, R. (2012), "Innovations and Curriculum Development for Engineering Education and Research in India", Procedia - Social and Behavioral Sciences, Vol. 56 No. 8, pp. 685-690.

44. Park, S., Henkin, A.B. and Egley, R. (2005), "Teacher team commitment, teamwork and trust: exploring associations", Journal of Educational Administration, Vol. 43 No. 4/5, pp. 462-479.

45. Paullay, I., Alliger, G. and Stone-Romero, E. (1994), “Construct validation of two instruments designed to measure job involvement and work centrality", Journal of Applied Psychology, Vol. 79, pp. 224-8.

46. Raju, P.M. and Srivastava, R.C. (1994), "Factors contributing to commitment to the teaching profession", International Journal of Educational Management, Vol. 8 No. 5, pp. 7-13.

47. Rickards, T., and Moger, S. (1999), Handbook for Creative Team Leaders, Gower Publishing, Aldershot.

48. Ruiz, J.L., Segura, J.V. and Sirvent, I. (2015), "Benchmarking and target setting with expert preferences: An application to the evaluation of educational performance of Spanish universities", European Journal of Operational Research, Vol. 242 No. 2, pp. 594-605.

49. Rus, C.L., Chirică, S., Raţiu, L. and Băban, A. (2014), "Learning Organization and Social Responsibility in Romanian Higher Education Institutions”, Procedia - Social and Behavioral Sciences, Vol. 142, pp. 146-153.

50. Salas, E., Stagl, K.C. and Burke, C.S. (2004), "25 years of team effectiveness in organizations: research themes and emerging needs", in Cooper, C.L. and Robertson, I.T. (Eds), International Review of Industrial and Organizational Psychology, Vol. 19, John Wiley and Sons, Chichester, pp. 47-91.

51. Senge, P. (1990), The Fifth Discipline: The Art and Practice of the Learning Organization, Doubleday, New York.

52. Stehr, N. (2002), Knowledge and Economic Conduct: The Social Foundations of the Modern Economy, University of Toronto Press, Toronto.

53. Sweet, C., Sweet, T., Rogers, B., Heritage, V. and Turner, M. (2007), "Developing a benchmark for company-wide sales capability", Industrial and Commercial Training, Vol. 39 Issue: 1, pp.18-26. 
54. Thompson, F., Baughan, D. and Motwani, J. (1998), “A case of innovative integration of high-performance work teams", Journal of Workplace Learning, Vol. 10 No. 3, pp. 157-164.

55. Umashankar, V. and Dutta, K. (2007), "Balanced scorecards in managing higher education institutions: an Indian perspective", International Journal of Educational Management, Vol. 21 No. 1, pp. 54-67.

56. Van Buren, M.E. and Werner, J.M. (1996), "High performance work systems", Business and Economic Review, Vol. 43, pp. 15-23.

57. Varney, G.H. (1994), “Control and autonomy: the primary determinant of successful applications for self-managing work teams", in Beyerlein, M.M. and Johnson, D.A. (Eds), Advances in Interdisciplinary Studies of Work Teams, Vol. 1, Theories of Selfmanaging Work Teams, Jai Press, Greenwich, CT, pp. 103-108.

58. Vlãsceanu, L., Grünberg, L., \& Parlea, D. (2004). Quality Assurance and Accreditation: A Glossary of Basic Terms and Definitions. Bucharest: Unesco-Cepes Papers in Higher Education.

59. Warrick, D. D. (2016), "What Leaders Can Learn About Teamwork and Developing High Performance Teams from Organization Development Practitioners", Performance Improvement, Vol. 55 No. 3, pp. 13-21.

60. World Declaration on Higher Education (1998), "Higher education in the twenty-first century: vision and action", Paper presented at World Conference on Higher Education, Paris. 
Figure 1 - The Proposed Model

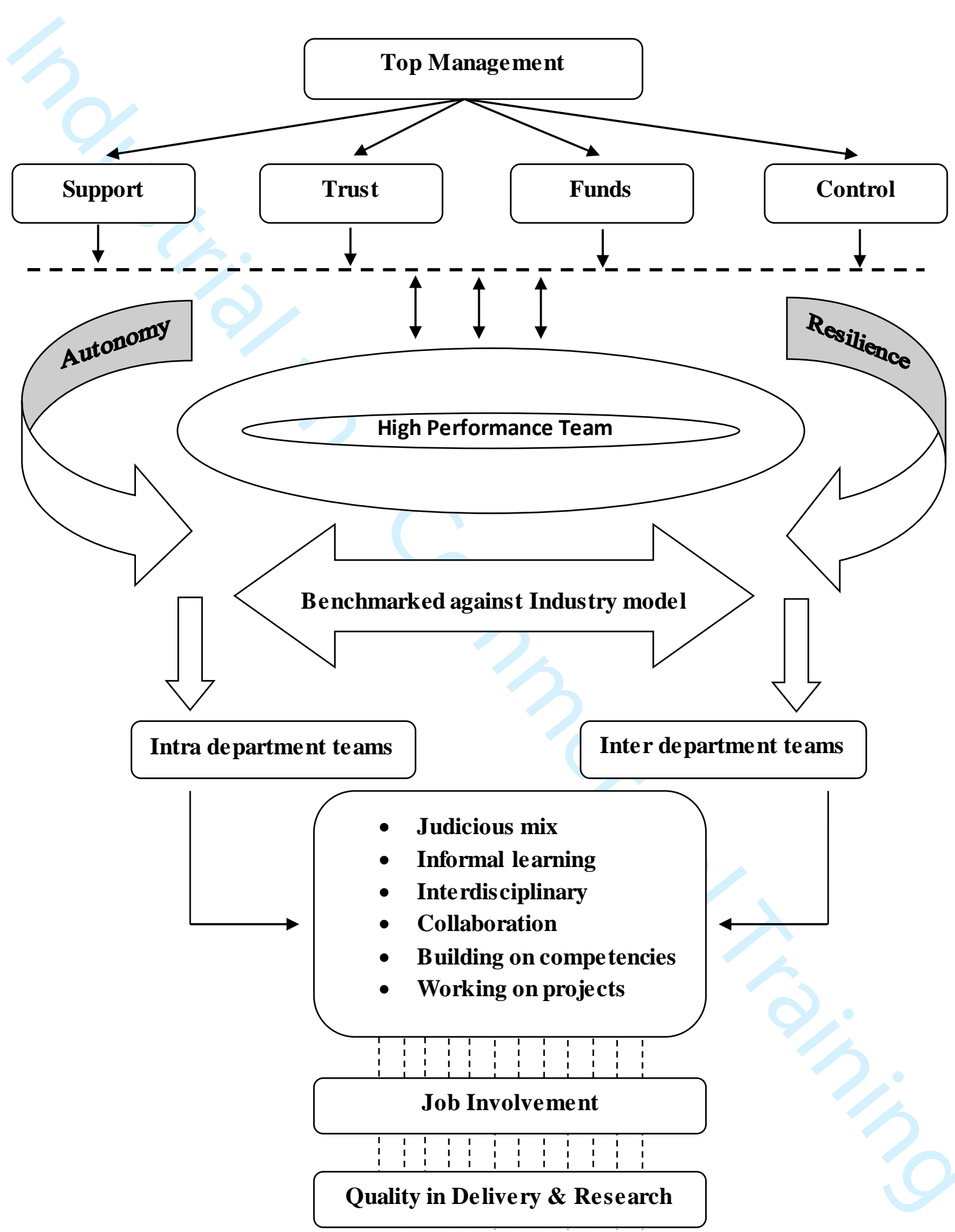


Figure 2-Impact of implementing HPTs

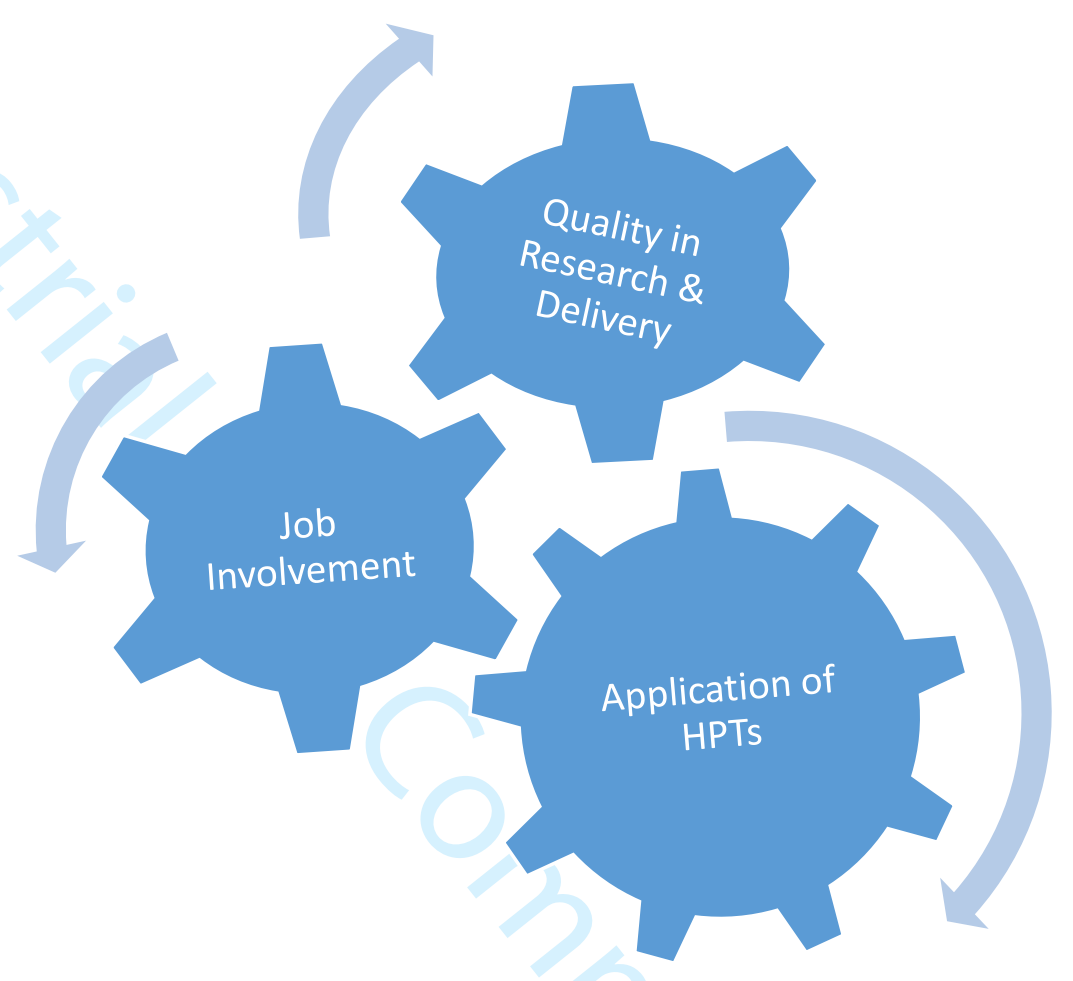

1

2

5

6

7

8

10

11

12

13

14

15

16

17

18

19

20

21

22

23

24

25

26

27

28

29

30

31

32

33

34

35

36

37

38

39

40

41

42

43

44

45

46

47

48

49

50

51

52

53

54

55

56

57

58

59

60 